\title{
The Implication of Socioeconomic Profile on Prognosis and Management Programs in Heart Failure Patients
}

\author{
Filipa Marques*, Cândida Fonseca, Pedro Sarmento, Inês Araújo, Cecília Shinn, Ana Leitão and \\ Fátima Ceia
}

\section{S. Francisco Xavier Hospital, Oral Anticoagulation Clinic, Outpatient Clinic and Internal Medicine Ward III, Estrada do Forte do Alto do Duque, 149-005 Lisbon, Portugal}

\begin{abstract}
Introduction: Little is known about the obstacles to patients' compliance to Heart Failure (HF) treatment. Heart Failure management programs seem to be a strategy to overcome these problems.

Aim: To evaluate in HF outpatients the role that socioeconomic characteristics and knowledge about the disease play in their compliance to treatment and long term mortality.

Population and methods: We conducted a prospective study of consecutive HF outpatients attending our HF Clinic. Structured questionnaires directed to the patient or care giver were used. Patients' socio-economic characteristics and understanding of the disease, as well as, predictors of long term mortality were accessed.

Results: We included 59 consecutive NYHA II-III HF patients, age $70.5 \pm 11.9$ years. Sixty three percent were male and $59.3 \%$ had left ventricular systolic dysfunction. Most patients had multiple comorbidities, were polymedicated, lived with their family and belonged to middle-low or low Graffar socioeconomic class. Eighty five percent were retired, median monthly income was $350 €, 41.5 \%$ had primary education and $22.6 \%$ were illiterate. More than half did not know they had HF, what HF was nor its main symptoms/ signs. Four year mortality was $23.6 \%$. Not knowing "what HF is" was the unique predictor of long-term mortality ( $p=0.035$; OR 0.097; CI: 0.011-0.846).

Conclusions: In our study Heart Failure patients were elderly, retired, and frequently dependent. Literacy was predominantly low. The need of polypharmacy, poor income and poor understanding of the disease were the rule. The later was even a predictor of long term mortality. Heart Failure management programs must be tailored to the needs of their users, taking into account their social environment.
\end{abstract}

Key Words: Heart failure, socioeconomic profile, heart failure management programs, outcome.

\section{INTRODUCTION}

Heart failure incidence and prevalence have been increasing in the past years in Europe as well as in the United States [1]. Two percent of the population is currently affected with continuous growth predicted over the next two decades, which will require special attention by health organizations [2].

Hypertension and Coronary Artery Disease are singly and together the most frequent aetiologies of HF in so-called developed countries, such as Portugal [2].

The EPICA study (Epidemiologia da Insuficiência Cardíaca e Aprendizagem), carried out in an outpatient setting in Portugal, demonstrated a prevalence of $4.36 \%$ in our country, which tends to be higher among women $(4.38 \% v s$. $4.33 \%$ ), and increases exponentially with age, reaching $16 \%$ after 80 years of age [3].

*Address correspondence to this author at the Oral Anticoagulation Clinic, Outpatient Clinic and Internal Medicine Ward III, Estrada do Forte do Alto do Duque, 149-005 Lisbon, Portugal; Tel: 00351966370 694; Fax: 00351 213017 958; E-mail: filipasmarques@sapo.pt
Heart Failure has been proven to have poor prognosis, with higher mortality than malign cancers altogether, as well as colon, breast and prostate carcinoma [4,5], and tends to be undervalued by health professionals and patients.

This disease consumes 1-2\% of Health Resources in developed countries [6,7], of which $75 \%$ of the budget is spent on hospitalization, which makes management of HF in the outpatient setting a priority [8-10].

Several attempts have been made to implement measures capable of reducing morbidity, hospital admissions and mortality. Multiple studies and meta-analyses have demonstrated that Disease Management Programs for Heart Failure (DMPs) reduce HF morbidity and mortality. Despite the benefits, the best approaches adopted for DMPs have not yet been defined, mainly because countries employ different strategies according to the health care system and dominant political opinions. It may even be different within the same country [11]. It is well known that patient and health professional education and counseling must be always present, even though the content, subjects, location and duration of the intervention may vary [12]. Nevertheless, the most im- 


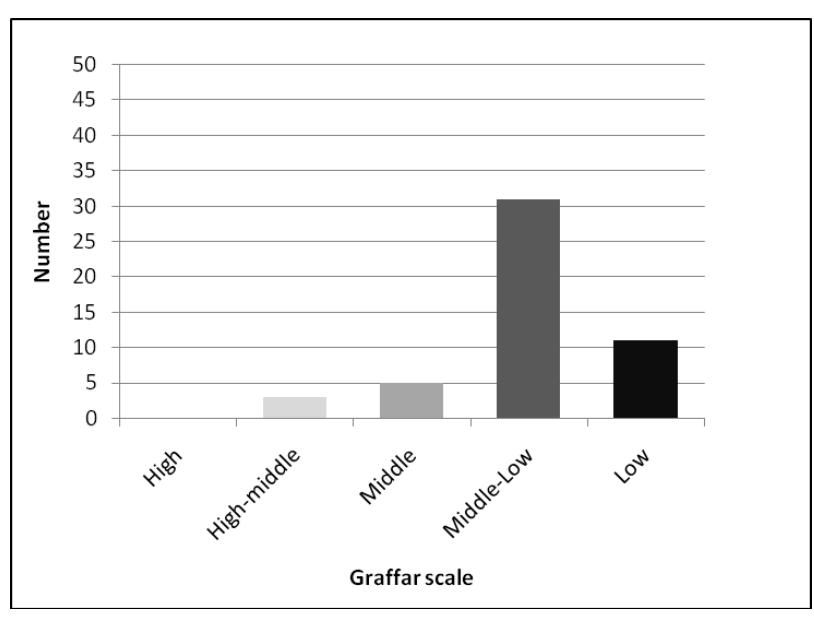

Fig. (1). Patients distribution according to social-economics Graffar scale.

portant aspect is that they should supply the needs of the population they serve [13].

Implementation of an outpatient clinic for the follow-up of HF patients ensures a bond between acute HF hospital units and primary health care, reducing admission time and preventing readmission.

Comorbidities usually associated with HF have already been shown to worsen prognosis in these patients. Less well studied factors such as socioeconomic level have been pointed out by some authors as emerging risk factors in HF evolution [14].

\section{Aim of the Study}

To evaluate in HF outpatients the role that socioeconomic characteristics and knowledge about the disease play in their compliance to treatment and long term mortality, with the goal of designing a broader HF management program better adapted to our local population needs.

\section{POPULATION AND METHODS}

We conducted a prospective study using a self-made questionnaire which was applied to outpatients and/or health care providers on the day of the appointment.

During a three month period, from October to December 2003, all patients with HF diagnosis, according to European Society of Cardiology [1] criteria that were referred for an appointment for the first time were included in the study.

In the questionnaire we recorded socioeconomic characteristics, knowledge of disease and other potential obstacles to doctor/nurse/patient communication and medication compliance. For complementary information their clinical file was reviewed.

Economic conditions were evaluated by their professional situation (active worker, retired, unemployed), monthly income, housing situation (house owner, living with family members, rented house or social housing) and housing ability (presence of stairs, lift, humidity, temperature, building age).
Regarding to literacy, education level was assessed with the intention to discover other potential obstacles to medication compliance. Patients were grouped according to high, high-middle, middle, middle-low and low class according to the adapted Graffar Scale $[15,16]$.

All medication taken was recorded as well as yes/no answers to a simple questionnaire to evaluate patients' knowledge of their own HF disease. The questions were as follows: do you know you have HF? Do you know what HF is? Do you know the main symptoms of HF? Do you know signs of decompensated HF? Do you know the importance of weighing frequently? Do you know the importance of low salt intake? Do you know that you must not interrupt medication? Do you know how to handle fluid overload? These data were supplied by the patient or caregiver, using a standardized interview.

Through interview and consultation of clinical files, HF was characterized according to: left ventricular ejection fraction (LVEF) [systolic dysfunction (LVEF $\leq 45 \%$ ), preserved ejection fraction (LVEF $>45 \%$ )]; aetiology (coronary artery disease, hypertension, cardiomyopathies, toxic, endocrine, nutritional disease, among others) [1] and severity of symptoms [New York Heart Association (NYHA) functional class]. We also recorded associated comorbidities (diabetes, chronic renal disease, anaemia, dyslipidemia, hyperuricemia, respiratory disease, chronic liver disease, thyroid dysfunction, osteoarthicular disease, peripheral vascular disease, cerebrovascular disease, gastro-intestinal disease, cancer and psychiatric diseases).

Long term mortality was analyzed in survivors and nonsurvivors after a follow-up period of four years.

The results were expressed in measures of central tendency (mean, standard deviation) and frequency tables (values expressed in absolute numbers and percentages). Comparisons with survivors and non-survivors groups were made by Student $t$ test (for quantitative variables) and by the chisquare test (for qualitative variables). Associations between the dependent variable and covariables were determined using bivariate analysis. The statistical significance level was established at $5 \%(\mathrm{p}<0.05)$.

All patients signed a written consent and the study was conducted under the ethical national committees'.

\section{RESULTS}

Table 1 summarizes baseline demographic and clinical characteristics of the eligible patients. We included 59 consecutive HF outpatients, NYHA classes II-III. Most were male and had HF due to left ventricular systolic dysfunction.

Three fourths had several associated comorbidities; the most frequently were dyslipidemia (32.2\%), diabetes $(25.4 \%)$, hyperuricemia $(20.3 \%)$ and degenerative osteoarthicular disease $(15.3 \%)$. The majority were polymedicated $(88.0 \%) ; 54.2 \%$ using four or more HF drugs, besides medication necessary to treat comorbidities.

With regards to socioeconomic data presented in Table $\mathbf{2}$, $85.0 \%$ of patients lived with their family (spouse and/or offspring) however, $13.2 \%$ lived alone without any support. Some degree of functional disability was reported by $43.7 \%$ 
Table 1. Baseline Demographic and Clinical Characteristics of Participants (Total and Followed According Outcome: Survivors and Non-Survivors)

\begin{tabular}{|c|c|c|c|}
\hline & \multirow{2}{*}{$\begin{array}{l}\text { Patients Included } \\
\qquad(n=59)\end{array}$} & \multicolumn{2}{|c|}{ Followed-Up Patients (n=51) } \\
\hline & & $\begin{array}{l}\text { Survivors } \\
\quad(n=39)\end{array}$ & $\begin{array}{c}\text { Non-Survivors } \\
(\mathrm{n}=12)\end{array}$ \\
\hline \multicolumn{4}{|c|}{ Gender, $\mathrm{n}(\%)$} \\
\hline Male & $37(62.7)$ & $26(66.7)$ & $7(58.3)$ \\
\hline Female & $22(37.3)$ & $13(33.3)$ & $5(41.7)$ \\
\hline Age (mean years, SD) & $70.5 \pm 11.9$ & $71.2 \pm 10.6$ & $69.8 \pm 12.8$ \\
\hline Systolic Dysfunction, n (\%) & $35(59.3)$ & $24(61.5)$ & $6(50.0)$ \\
\hline \multicolumn{4}{|l|}{ HF Aetiology, n (\%) } \\
\hline Ischemic & $18(30.5)$ & $12(30.8)$ & $3(25.0)$ \\
\hline Hypertensive & $27(45.8)$ & $19(48.7)$ & $5(41.7)$ \\
\hline Other* & \multirow{2}{*}{$21(35.6)$} & $14(35.9)$ & $4(33.3)$ \\
\hline Number of Comorbidities, $\mathrm{n}(\mathrm{p}$ & & & \\
\hline 0 & $16(27.1)$ & $9(23.1)$ & $3(25.0)$ \\
\hline $1-2$ & $26(44.1)$ & $17(43.6)$ & $6(50.0)$ \\
\hline $3-4$ & $15(25.4)$ & $11(28.2)$ & $3(25.0)$ \\
\hline$\geq 5$ & $2(3.4)$ & $2(5.1)$ & - \\
\hline
\end{tabular}

*Other HF aetiology: cardiomyopathies, drugs, toxic, endocrin and nutritional disease.

of patients but only $15.3 \%$ had specific health care help (help at home, day care or nursing home). Only $64.4 \%$ of patients were able to prepare their own medication. While some patients report that they usually attended appointments accompanied by a family member $(32.2 \%)$, only half of these family members $(18.6 \%)$ were actually the main health care provider.

Regarding their economic conditions, $85.2 \%$ of the participants were retired; average monthly income was $387.2 \pm$ $249.9 €$ (median $350 €$ ); $37.3 \%$ lived in a rented house, $28.8 \%$ owned their home and $18.6 \%$ lived with their family. Inadequate housing conditions were reported by $18.6 \%$ most related with a lack of lift.

The educational level of the patients was low, $22.6 \%$ had no school education and $41.5 \%$ had first level education. Only $35.8 \%$ (19) patients had secondary or higher studies (level $\geq 5$ years).

Concerning the knowledge of the disease (Table 3), most patients did not know they had HF, what HF was, or what the main symptoms or signs of decompensation were.

Few patients $(15.3 \%)$ knew about the importance of regular weighing, of salt intake restriction and how to deal with signs of fluid overload.

Although most family members/care givers understood what HF was, the main symptoms, the importance of regular weighting and the signs of decompensation, only few knew about the importance of restricting salt intake or how to deal with fluid overload. Nevertheless, all of them knew the importance of medication compliance.

The mean time of follow-up was $48 \pm 14.1$ months for 51 patients. Eight patients were lost to follow-up (13.6\%). During this period $12(23.5 \%)$ patients died, all of them had family support; $83.3 \%$ had less than four years of school education, didn't know what HF was $(\mathrm{p}=0.034)$ nor knew how to deal with fluid overload. Regarding other socioeconomic and clinical characteristics all patients belong to middle-low or low Graffar class, none of them was an active worker, and most were taking three or more HF drugs.

Using logistic regression analysis adjusted to age and gender with death as the dependent variable and socioeconomic variables as independent, the only independent predictor for long term mortality was "Knowing what HF is" ( $p=$ 0.035; OR 0.097 CI: 0.011-0.846), however "Knowing the importance of medication compliance" also showed a tendency toward a better prognosis $(\mathrm{p}=0.068)$. The remaining variables did not significantly influence long term mortality in this population.

\section{DISCUSSION}

Analysis of the results reflect the national patterns of segregation of our elderly $\mathrm{HF}$ patients and those undergoing hardship, which turns medication compliance difficult, and brings problems in accessing to medical care and diagnostic exams.

The family is still the primary support for elderly people, with regards to daily health care and palliative care. 
Table 2. Population Socioeconomic Data According to Outcome

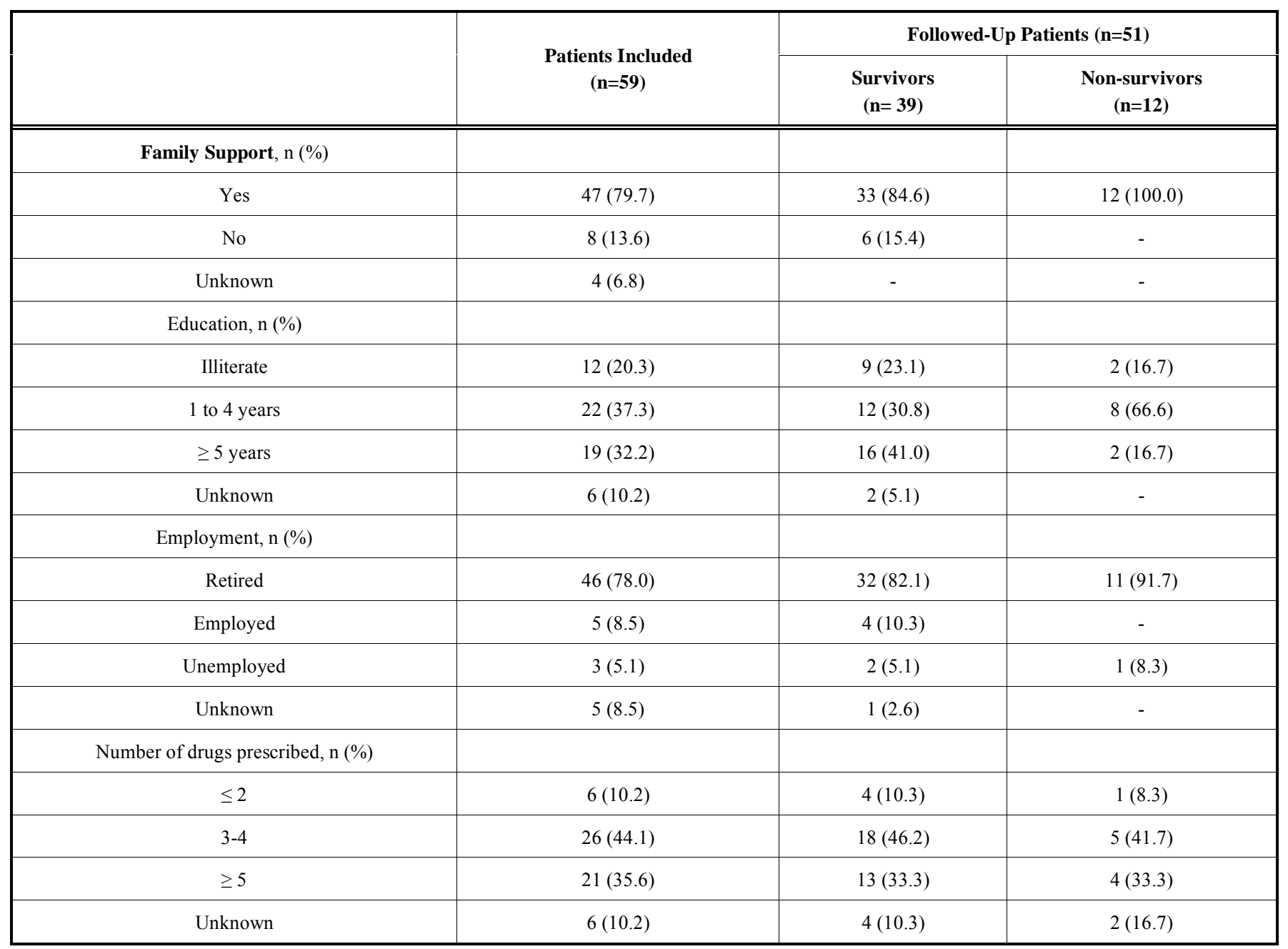

Table 3. Results of Interview Questionnaire Done to Patients and Care-Givers About HF, n (\%) of "Correct" Answers

\begin{tabular}{|c|c|c|}
\hline & $\begin{array}{c}\text { Patient } \\
(\mathbf{n}=\mathbf{5 9})\end{array}$ & Care-Giver \\
\hline \hline What is HF? & $25(42.4)$ & $7(63.6)$ \\
\hline Know you have HF? & $25(42.4)$ & - \\
\hline Main symptoms & $27(45.8)$ & $6(54.5)$ \\
\hline Signs of decompensation & $26(44.1)$ & $5(45.5)$ \\
\hline Importance of regular weight & $9(15.3)$ & $8(72.7)$ \\
\hline Importance of salt restriction & $23(39.0)$ & $2(18.2)$ \\
\hline Dealing with fluid overload & $9(15.3)$ & $1(9.1)$ \\
\hline Medication compliance & $46(78.0)$ & $10(90.9)$ \\
\hline
\end{tabular}

However, only few patients' family members were actually daily care-givers and most of them did not know about the disease and adequate care. Housing conditions, namely lack of lifts, complicates patient's daily-life and limits their ability to adopt a healthier lifestyle (such as regular exercise) which is an essential part of non-pharmacological treatment of HF.

In these patients an insufficient economic resource was also founded, the average income being almost similar to the National Minimum Wage (€356.60 in 2005). This has an effect on medication compliance that should be assessed throw government support, already used in other chronic diseases, such as diabetes and cancer, which have similar prognoses. It is well known that increases in complexity of medication regimes reduce patient compliance, which is one of the factors most frequently identified as being the cause of decompensation, often leading to hospital readmission.

As far as disease knowledge is concerned, patients provided rather incomplete answers, due to low literacy levels (in some cases illiteracy) as well as lack of social support, and these are determinant factors when organizing personalized multi-disciplinary education. Teaching methodology must necessarily be simple and continuous, without resorting to modern technology, and education must be adapted for patients and caregivers.

Patients with good social support (especially with regards to spouses) have been shown to increase the quality of their 
life, and reduce hospital readmission and mortality [17]. Nevertheless, in this study we didn't find these results probably due to the small dimension of study's population and because few patients had no family support.

The negative impact that low socioeconomic level has on health, in particular on cardiovascular disease, was recognized for a long time. However, it has only been considered a risk factor for cardiovascular disease in the last couple of years, and since then is subject of discussion among health professionals $[18,19]$. Not much is known about its role in HF.

In 1999, a 20 year follow-up study identified, besides classical risk factors for HF, low literacy level as a predisposing factor for the disease [6]. In the 80's and 90's, factors such as low literacy [9] and income [18], lack of social support [20], lack of specialized jobs [21, 22], and not owning a house or vehicle [23], were associated with increased mortality.

Socioeconomic hardship is associated with high levels of hospital admission and poor prognosis in HF patients, even though the mechanisms have not been well defined [24-27]. A literature review was carried out in 2002, based on a digital search, which included several highly acclaimed journals in this area. Only eight articles were found (published between 1966 and 2000) that relate HF to socioeconomic profile [28]. These studies, carried out in the United States, England and Spain, mainly demonstrate that patients with lower levels of income and less education had less access to cardiology appointments; the elderly, low income patients and those without private health care were placed last on transplant lists; patients with lower income had higher hospital admission rates and those with lower social status, with less income, tended to be more symptomatic and have more functional limitations.

A Scottish study published in 2004, which included 2186 adults with HF, treated in Primary Care settings, demonstrated that even though HF incidence is higher in populations that experience more hardships (44\% higher risk), this population also had less annual medical appointments $(23 \%$ less) and greater mortality (estimated average survival of 3.5 to 4.4 for better-off populations and 2.8 for less well-off populations). However, contrary to belief, prescription of medications that have been proven to improve disease prognosis was similar for all socioeconomic levels [27].

A recent study that evaluates the role of socioeconomic factors in HF prognosis in Brazil, and presents socioeconomic data very similar to the data in our study, identified that factors that predict a poor prognosis are low monthly income, not owning a vehicle, and being treated in public hospitals, whereas illiteracy was associated with a tendency towards worse prognosis [24].

Even though we identified socioeconomic hardship, in our study population, we were unable to associate these variables with long-term mortality due to HF; however it seems wise to assume that lack of knowledge about the disease, which is a predictor of poor prognosis, could be related to illiteracy, or social hardship.

An important limitation of our study is the fact that we studied a small population of a HF Clinic in a Tertiary Hos- pital, even though there was no selection bias. Greater numbers of patients would probably allow us to make more significant correlations between patient socioeconomic profile and prognosis. However, this analysis enables us to draw some important conclusions to improve the HF management program in our hospital, with a better suited methodology to the population needing our care.

\section{CONCLUSION AND COMMENTS}

Low socioeconomic level is very common among elderly patients with HF and is a determining factor for patients' education in HF management programs. Lack of knowledge about the disease is an independent predictor of long-term mortality, and lack of knowledge about the importance of medication compliance tends to worsen prognosis. It is thus vital to establish educational strategies adapted to patients' limitations as an essential part of local HF management programs.

We need a more adequate approach to HF that not only includes classical risk factors but also social and economic problems. It is also crucial that government health-care organizations made aware of these problems so that they can improve the support delivered.

\section{REFERENCES}

[1] ESC guidelines for the diagnosis and treatment of acute and chronic heart failure 2008: the Task Force for the diagnosis and treatment of acute and chronic heart failure 2008 of the European Society of Cardiology. Developed in collaboration with the Heart Failure Association of the ESC (HFA) and endorsed by the European Society of Intensive Care Medicine (ESICM). Eur J Heart Fail 2008; 10: 933-89.

[2] Fonseca C, Ceia F, Brito D, Madeira H. How patients with heart failure are managed in Portugal. Eur J Heart Fail 2002; 4: 563-6.

[3] Ceia F, Fonseca C, Mota T, et al. Aetiology, comorbidity and drug therapy of chronic heart failure in the real world: the EPICA substudy. Eur J Heart Fail 2004; 6: 801-6.

[4] Quinn MJ, Babb P, Brock A, Kirby LJJ. Cancer trends in England and Wales 1950-1999. studies on medical and population subjects No. 66; Office for National Statistics: London 2001.

[5] Cowie MR, Wood DA, Coats AJ, et al. Survival of patients with a new diagnosis of heart failure: a population based study. Heart 2000; 83: 505-10.

[6] Berry C, Murdoch DR, McMurray JJ. Economics of chronic heart failure. Eur J Heart Fail 2001; 3: 283-91.

[7] Task Force of the Working Group on Heart Failure of the European Society of Cardiology. The treatment of heart failure. Eur Heart J 1997; 18: 736-53.

[8] Adams KF, Jr, Zannad F. Clinical definition and epidemiology of advanced heart failure. Am Heart J 1998; 135: S204-15.

[9] O'Connell JB. The economic burden of heart failure. Clin Cardiol 2000; 23: III6-10.

[10] Malcom J, Arnold O, Howlett JG, et al. Canadian Cardiovascular Society Consensus Conference guidelines on heart failure--2008 update: best practices for the transition of care of heart failure patients, and the recognition, investigation and treatment of cardiomyopathies. Can J Cardiol 2008; 24: 21-40.

[11] McDonald K, Conlon C, Ledwidge M. Disease management programs for heart failure: not just for the 'sick' heart failure population. Eur J Heart Fail 2007; 9: 113-7.

[12] van der Wal MH, Jaarsma T, van Veldhuisen DJ. Non-compliance in patients with heart failure; how can we manage it? Eur J Heart Fail 2005; 7: 5-17.

[13] Jourdain P, Funck F, Bellorini M, et al. Heart failure clinics. Concept, organization, results. Ann Cardiol Angeiol (Paris) 2002; 51: 248-53.

[14] Stewart S, Murphy NF, McMurray JJ, Jhund P, Hart CL, Hole D. Effect of socioeconomic deprivation on the population risk of inci- 
dent heart failure hospitalisation: an analysis of the Renfrew/Paisley Study. Eur J Heart Fail 2006; 8: 856-63.

[15] Amaro F. Escala de Graffar Adaptada. In: Costa, Ana Ma. Bérnard, et al. (1996) Curriculos Funcionais Lisboa 1990; Vol. II: IIE.

[16] Méndez H. Sociedad y Estratificatión. Ministerio de Salud y Desarrollo Social. Sistema Regional de Salud. Dirección de Promoción Social para la Salud 1995: pp. 23-47.

[17] Luttik ML, Jaarsma T, Veeger N, Tijssen J, Sanderman R, van Veldhuisen DJ. Caregiver burden in partners of heart failure patients; limited influence of disease severity. Eur J Heart Fail 2007; 9: 695-701.

[18] Smith GD, Carroll D, Rankin S, Rowan D. Socioeconomic differentials in mortality: evidence from Glasgow graveyards. BMJ 1992; 305: 1554-7.

[19] Philbin EF, Dec GW, Jenkins PL, DiSalvo TG. Socioeconomic status as an independent risk factor for hospital readmission for heart failure. Am J Cardiol 2001; 87: 1367-71.

[20] Ruberman W, Weinblatt E, Goldberg JD, Chaudhary BS. Psychosocial influences on mortality after myocardial infarction. $\mathrm{N}$ Engl $\mathrm{J}$ Med 1984; 311: 552-9.

[21] Rose G, Marmot MG. Social class and coronary heart disease. $\mathrm{Br}$ Heart J 1981; 45:13-9.
[22] Pincus T, Esther R, DeWalt DA, Callahan LF. Social conditions and self-management are more powerful determinants of health than access to care. Ann Intern Med 1998; 129: 406-11.

[23] Kaplan GA, Keil JE. Socioeconomic factors and cardiovascular disease: a review of the literature. Circulation 1993; 88:1973-98.

[24] de Campos Lopes CB, Yamada AT, Araujo F, Pereira Barreto AC, Mansur AJ. Socioeconomic factors in the prognosis of heart failure in a Brazilian cohort. Int J Cardiol 2006; 113:181-7.

[25] Struthers AD, Anderson G, Donnan PT, MacDonald T. Social deprivation increases cardiac hospitalisations in chronic heart failure independent of disease severity and diuretic non-adherence. Heart 2000; 83:12-6.

[26] MacIntyre K, Capewell S, Stewart S, et al. Evidence of improving prognosis in heart failure: trends in case fatality in 66547 patients hospitalized between 1986 and 1995. Circulation 2000; 102: 112631.

[27] McAlister FA, Murphy NF, Simpson CR, et al. Influence of socioeconomic deprivation on the primary care burden and treatment of patients with a diagnosis of heart failure in general practice in Scotland: population based study. BMJ 2004; 328: 1110.

[28] Blair AS, Lloyd-Williams F, Mair FS. What do we know about socioeconomic status and congestive heart failure? A review of the literature. J Fam Pract 2002; 51: 169.

(C) Marques et al.; Licensee Bentham Open.

This is an open access article licensed under the terms of the Creative Commons Attribution Non-Commercial License (http://creativecommons.org/licenses/by-nc/3.0/) which permits unrestricted, non-commercial use, distribution and reproduction in any medium, provided the work is properly cited. 